\title{
Prevalence of helminthes, pneumonia and hepatitis in Kirkuk slaughter house, Kirkuk, Iraq
}

\author{
M.A. Kadir ${ }^{1}$, N.H. Ali ${ }^{2}$ and R.G.M. Ridha ${ }^{2}$ \\ ${ }^{1}$ College of Medicine,Kirkuk University, ${ }^{2}$ Veterinary Hospital, Kirkuk, Iraq
}

\begin{abstract}
The study was carried out in Kirkuk official slaughter house for the period from the beginning of July 2009 to end of June 2010. Macroscopic examination was performed to demonstrate the distribution of hydatid cyst, fascioliasis, lung worms, pneumonia and hepatitis and their impact on economic losses in the governorate. The number of animals slaughtered during the period of study was: sheep 50518, cattle 16177, goats 7662 , buffalos 48 and camels 24 . In sheep, the rate of hydatid cysts was $0.77 \%$, with the highest rate was in autumn; liver flukes $0.36 \%$ with the highest rate in summer $0.33 \%$; lung worms $0.19 \%$, the highest was in winter $0.27 \%$; pneumonia $0.58 \%$, the highest was in summer $0.74 \%$ and hepatitis was $0.32 \%$, the highest was in winter $0.42 \%$. In cattle, the rate of hydatid cysts was $1.70 \%$, the highest was in summer $1.65 \%$; liver fluke $1.27 \%$, the highest was in winter $1.57 \%$; lung worms $0.71 \%$, the highest was in spring $0.94 \%$; pneumonia $0.79 \%$, the highest was in summer $0.88 \%$ and hepatitis $1.12 \%$, the highest was in summer $1.16 \%$. In goats, no hydatid cysts were seen; the rate of liver fluke was $0.14 \%$, with the highest rate was in winter $0.51 \%$; lung worms was $0.03 \%$ and only seen in winter and autumn; pneumonia $0.14 \%$, the highest was in summer $0.25 \%$; hepatitis $0.05 \%$ and only seen in summer and autumn. In buffaloes and camels, only 1 case of fascioliasis was seen for each in spring. The economic losses due to condemnation of organs of infected animals in Iraqi diners was: Sheep 4.840.00 millions, cattle 5.434.000 millions and goats 156.000 thousands. The overall economic losses were 10.430.000 Iraqi diners.
\end{abstract}

Keywords: Prevalence; Helminthes; Pneumonia; Hepatitis.

Available online at http://www.vetmedmosul.org/ijvs

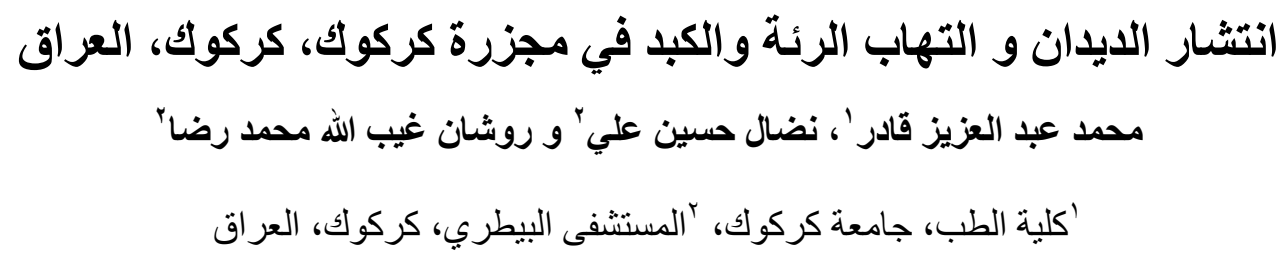

الخلاصة

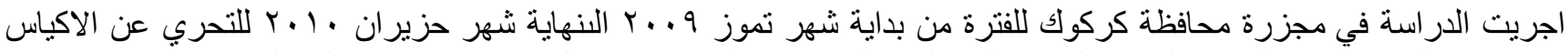

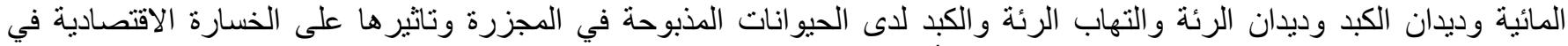

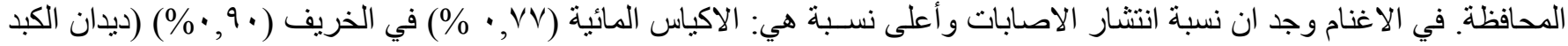

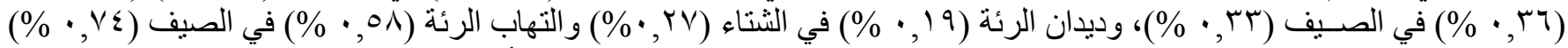

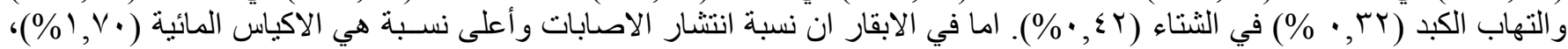

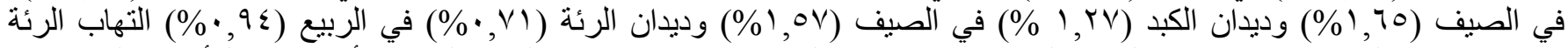

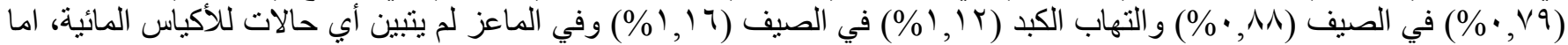

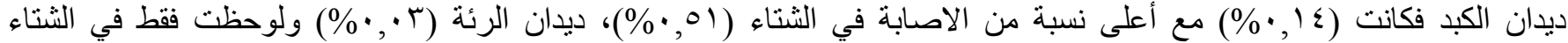

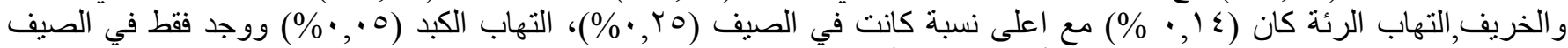

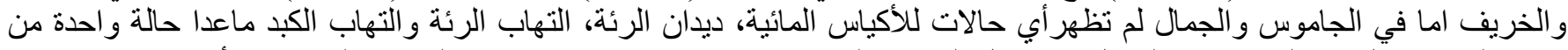

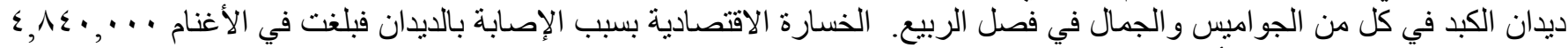

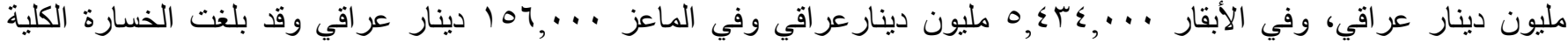

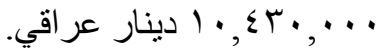




\section{Introduction}

Parasitic diseases are of crucial economic importance in domestic animals in all continents, probably constitute one of the major obstacles to the development of profitable livestock industries and are of crucial economic importance in all continents (1-3).

Echinococcosis is a zoonotic infection caused by $E$. granulosus, its definitive host is dog and other canids, and domestic animals and human beings are intermediate hosts (4). There are no reliable methods for routine diagnosis of infections in living animals; the most reliable diagnostic method is at post-mortem examination (3).

In Baghdad slaughter house (5) found $4.5 \%$ of sheep and $5.0 \%$ of cattle were infected with hydatid cysts. In Erbil (6) found $27.4 \%$ of goats and $22.3 \%$ of cattle were infected with hydatid cysts. In Kirkuk (7) reported the rate of hydatid cysts in sheep $1.17 \%$, goats $0.32 \%$, cattle $4.33 \%$ and buffaloes $2 \%$.

Fascioliasis is widely distributed disease in Iraq; it is present in all parts of the country (8). In AL-Sheikh Omer slaughter house, in Baghdad (9) found that the rate of fascioliasis was $7.1 \%$ in sheep and $27 \%$ in cattle. In Basrah (10) reported that the rate of infection in cattle and sheep was $3.2 \%$ and $0.7 \%$ respectively. In Babylon (11) found that the rate of infection in cattle with $F$. gigantica was $19.3 \%$. The highest rate was in summer $25.5 \%$ and the lowest was in winter $14.3 \%$.

Lung worms also consider one of common parasitic infection in Iraq. In Mosul abattoir (12) reported 37\% (medium to heavy infestation during winter. In Kirkuk (7) found that the distribution of lung worm in sheep, goats and cattle were $0.55 \%, 0.22 \%$ and $2.98 \%$ respectively.

The present study aimed to show the prevalence of hydatid cysts, fascioliasis, lung worm, hepatitis and pneumonia in addition to their impact on economic state.

\section{Materials and methods}

The study was carried out in Kirkuk slaughter house for the period from the beginning of July 2009 to end of June 2010. The data was collected by regularly visiting the municipal slaughter house three times weekly. The numbers of animals examined were 50518 sheep, 16177 cattle, 7661 goats 48 buffaloes and 24camels. All slaughter animals were of local breeds.

Liver and lungs of slaughtered animals were inspected macroscopically by veterinarian to show the presence of hydatid cysts, fascioliasis, lung worm in addition to pneumonia and hepatitis. In all pneumonia and hepatitis cases, no parasites were detected.

The total economic losses due to condemnation of infected livers and lungs were estimated by finding the average weight of infected liver and lungs which is estimated by total weight of infected organs divided by number of weight organs (13).

The data was analyzed using Chi- square analysis $\left(\mathrm{x}^{2}\right)$, the test was used to find the variation prevalence during the period of study (14).

\section{Results}

The total number of sheep, cattle, goats, buffaloes and camels slaughtered in Kirkuk official slaughter house during the period from beginning of July 2009 till end of June 2010 were 50518, 16177, 7662, 48 and 24 respectively.

The number of ruminant slaughtered varies in different seasons. The number of sheep slaughtered was higher in spring followed by summer, winter and autumn. The number of cattle slaughtered was highest in winter followed by autumn, spring and summer, while the number of goats slaughtered was highest in autumn followed by summer. In addition to that only 48 buffaloes and 24 camels were slaughtered; their numbers were highest during summer months (Table 1).

Table (1) Number of animals slaughtered in Kirkuk slaughter house according to seasons.

\begin{tabular}{lcccc}
\hline Animals & Winter & Spring & Summer & Autumn \\
\hline Sheep & 2388 & 3037 & 4388 & 1987 \\
& 4985 & 7502 & 4630 & 5146 \\
& 4054 & 5048 & 3201 & 4052 \\
\hline Total 50518 & 11427 & 15587 & 12219 & 11285 \\
\hline Cattle & 873 & 888 & 775 & 880 \\
& 2504 & 1845 & 1069 & 1933 \\
& 1213 & 1100 & 1675 & 1422 \\
\hline Total 16177 & 4590 & 3833 & 3519 & 4235 \\
\hline Goats & 624 & 119 & 470 & 712 \\
& 491 & 356 & 698 & 1258 \\
& 252 & 604 & 1218 & 860 \\
\hline Total 7662 & 1367 & 1079 & 2386 & 2830 \\
\hline Buffaloes & 3 & 4 & 5 & 4 \\
& 1 & 11 & 8 & 3 \\
& 3 & 1 & 4 & 1 \\
\hline Total 48 & 7 & 16 & 17 & 8 \\
\hline Camel & 0 & 1 & 14 & 0 \\
& 2 & 0 & 2 & 2 \\
\hline Total 24 & 2 & 1 & 17 & 4 \\
\hline
\end{tabular}

The data in table 2 revealed that the rate of hydatid cysts infestation was highest in cattle $(1.75 \%)$ followed by sheep $(0.77 \%)$ while no positive cases were detected in goats, buffaloes and camels. Statistical analysis showed that there 
was significant different in the rate of infection between different groups of animals $(\mathrm{P}<0.01)$.

The distribution of fascioliasis in ruminants was highest in buffaloes $2.08 \%$ followed by cattle $1.27 \%$, sheep $0.36 \%$ and goats $0.14 \%$. No fasciola parasite was detected in slaughtered camel. Statistical analysis revealed significant difference between slaughtered animals $(\mathrm{P}<0.01)$.

For the distribution of lung worms among slaughtered ruminants, it was highest among slaughtered buffaloes $2.08 \%$ followed by cattle $1.27 \%$; sheep $0.19 \%$ and goats $0.03 \%$. No cases were detected in camels. The difference between slaughtered animals was significant $(\mathrm{P}<0.01)$. Hepatitis was observed in liver of slaughtered ruminants. The highest rate among cattle $1.12 \%$ followed by sheep $0.32 \%$ and goats $0.05 \%$, but no hepatitis observed among slaughtered buffaloes and camels. The difference between animals groups was significant $(\mathrm{P}<0.05)$. The rate of pneumonia among slaughtered ruminants was highest in cattle $0.79 \%$ followed by sheep $0.58 \%$ and goats $0.14 \%$. No pneumonia was observed in buffaloes and camel. Statistically there was significant difference between slaughtered animals $(\mathrm{P}<0.01)$.

The data in table (3) shows that the seasonal distribution of diseases in slaughtered ruminants was varied in different ruminants.

In sheep, the rate of hydatid cysts was highest in autumn $0.90 \%$, followed by winter $0.82 \%$, summer $0.78 \%$ and the lowest was in spring $0.63 \%$, The rate of liver fluke was highest in summer $0.43 \%$, followed by winter $0.37 \%$ and the lowest was in spring and autumn $0.33 \%$ for each. The lung worms were highest in winter $0.27 \%$, followed by summer $0.23 \%$, autumn $0.16 \%$ and spring $0.13 \%$ respectively. The rate of pneumonia was highest in summer $0.74 \%$ followed by spring $0.62 \%$, winter $0.54 \%$ and autumn $0.37 \%$. While the rate of hepatitis was highest in winter $0.42 \%$ followed by summer $0.37 \%$, spring $0.29 \%$ and autumn $0.26 \%$.

The data in table (4) indicates the rate of diseases in cattle. The rate of hydatid cysts was highest in summer $1.65 \%$ then spring $1.33 \%$, autumn $0.89 \%$ and winter $0.87 \%$. The rate of liver fluke was highest in winter $1.57 \%$, summer $1.28 \%$, autumn $1.25 \%$ and spring $0.94 \%$. The lung worm infection was highest in spring $0.94 \%$, followed by autumn $0.68 \%$ winter $0.67 \%$ and summer $0.54 \%$ respectively. Pneumonia was commonest in summer $0.88 \%$ followed by autumn $0.83 \%$, winter $0.74 \%$ and spring 0.73 $\%$. Hepatitis rate was highest in summer $1.16 \%$ followed by winter $1.13 \%$, spring $1.12 \%$ and was lowest in autumn $0.89 \%$.

The distribution of diseases according to seasons in goats indicate in table (5). No hydatid cysts was seen in goats during the period of study, Liver flukes was highest in winter $0.51 \%$, followed by spring $0.09 \%$, autumn $0.07 \%$ and summer $0.04 \%$, Lung worms rate was $0.07 \%$ in winter, $0.03 \%$ in autumn and there was no lungworms showed in spring and summer. Pneumonia rate in summer was $0.25 \%$ followed by winter $0.22 \%$ and spring $0.18 \%$. Hepatitis rate was $0.08 \%$ in summer and $0.07 \%$ in autumn.

Table (2) Prevalence of helminthes, hepatitis and pneumonia in ruminants.

\begin{tabular}{lcccccc}
\hline Animals & No. examined & Hydatid cysts (\%) & Liver fluke (\%) & Lungworms (\%) & Hepatitis (\%) & Pneumonia (\%) \\
\hline Sheep & 50518 & $0.77 \%$ & $0.36 \%$ & $0.19 \%$ & $0.32 \%$ & $0.58 \%$ \\
Cattle & 16177 & $1.75 \%$ & $1.27 \%$ & $1.27 \%$ & $1.12 \%$ & $0.79 \%$ \\
Goats & 7662 & 0 & $0.14 \%$ & $0.14 \%$ & $0.05 \%$ & $0.14 \%$ \\
Buffaloes & 48 & 0 & $2.08 \%$ & $2.08 \%$ & 0 & 0 \\
Camel & 24 & 0 & 0 & 0 & 0 & 0 \\
Chi Sq ${ }^{(\mathrm{X} 2}$ ) & & 196.163 & 216.983 & 134.391 & 202.435 & 38.312 \\
D.F. & & 4 & 4 & 4 & 4 & 4 \\
P value & & $\mathrm{P}<0.01$ & $\mathrm{P}<0.01$ & $\mathrm{P}<0.01$ & $\mathrm{P}<0.05$ & $\mathrm{P}<0.01$ \\
\hline
\end{tabular}

Table (3) Prevalence of infections in sheep in Kirkuk slaughter house according to seasons.

\begin{tabular}{lcccccc}
\hline Season & No. examined & $\begin{array}{c}\text { Hydatid cysts } \\
\text { NO. (\%) }\end{array}$ & $\begin{array}{c}\text { Liver fluke } \\
\text { N0. }(\%)\end{array}$ & $\begin{array}{c}\text { Lungworms } \\
\text { N0. }(\%)\end{array}$ & $\begin{array}{c}\text { Pneumonia } \\
\text { No. (\%) }\end{array}$ & $\begin{array}{c}\text { Hepatitis } \\
\text { N0. }(\%)\end{array}$ \\
\hline Spring & 15587 & $99(0.63 \%)$ & $51(0.33 \%)$ & $21(0.13 \%)$ & $97(0.62 \%)$ & $45(0.29 \%)$ \\
Summer & 12219 & $95(0.78 \%)$ & $53(0.43 \%)$ & $28(0.23 \%)$ & $91(0.74 \%)$ & $45(0.37 \%)$ \\
Autumn & 11285 & $102(0.90 \%)$ & $37(0.33 \%)$ & $18(0.16 \%)$ & $42(0.37 \%)$ & $29(0.26 \%)$ \\
Winter & 11427 & $94(0.82 \%)$ & $42(0.37 \%)$ & $31(0.27 \%)$ & $62(0.54 \%)$ & $48(0.42 \%)$ \\
\hline Total & 50518 & $390(0.77 \%)$ & $183(0.36 \%)$ & $98(0.19 \%)$ & $292(0.58 \%)$ & $167(0.32 \%)$ \\
\hline
\end{tabular}


The distribution of diseases in buffalos according to seasons indicated in table (6) No hydatid cysts, lung worms, pneumonia and hepatitis observed in slaughtered goats while only 1 buffalo was infected with liver fluke in spring.
In camels no cases of hydatid cysts, fascioliasis, lung worms, pneumonia and hepatitis were seen observed in slaughtered house, except one case of fascioliasis in spring (Table 7).

Table (4) Prevalence of infections in cattle in Kirkuk slaughter house according to season.

\begin{tabular}{lcccccc}
\hline Seasons & No. examined & Hydatid cysts & Liver fluke & Lung worms & Pneumonia & Hepatitis \\
\hline Spring & 3833 & $51(1.33 \%)$ & $36(0.94 \%)$ & $36(0.94 \%)$ & $28(0.73 \%)$ & $43(1.12 \%)$ \\
Summer & 3519 & $58(1.65 \%)$ & $45(1.28 \%)$ & $19(0.54 \%)$ & $31(0.88 \%)$ & $41(1.16 \%)$ \\
Autumn & 4235 & $80(0.89 \%)$ & $53(1.25 \%)$ & $29(0.68 \%)$ & $35(0.83 \%)$ & $38(0.89 \%)$ \\
Winter & 4590 & $86(0.87 \%)$ & $72(1.57 \%)$ & $31(0.67 \%)$ & $34(0.74 \%)$ & $60(1.13 \%)$ \\
\hline Total & 16177 & $275(1.70 \%)$ & $206(1.27 \%)$ & $115(0.71 \%)$ & $128(0.79 \%)$ & $182(1.12 \%)$ \\
\hline
\end{tabular}

Table (5) Prevalence of infections in goats in Kirkuk slaughter house according to season.

\begin{tabular}{lcccccc}
\hline Season & No. Examined & Hydatid cysts & Liver fluke & Lung worms & Pneumonia & Hepatitis \\
\hline Spring & 1079 & 0 & $1(0.09 \%)$ & 0 & $2(0.18 \%)$ & 0 \\
Summer & 2386 & 0 & $1(0.04 \%)$ & 0 & $6(0.25 \%)$ & $2(0.08 \%)$ \\
Autumn & 2830 & 0 & $2(0.07 \%)$ & $1(0.03 \%)$ & 0 & $2(0.07 \%)$ \\
Winter & 1367 & 0 & $7(0.51 \%)$ & $1(0.07 \%)$ & $3(0.22 \%)$ & 0 \\
\hline Total & 7662 & 0 & $11(0.14 \%)$ & $2(0.03 \%)$ & $11(0.14 \%)$ & $4(0.05 \%)$ \\
\hline
\end{tabular}

Table (6) Prevalance of infection in buffaloes according to seasons.

\begin{tabular}{lcccccc}
\hline Season & No. Examined & Hydatid cysts & Liver fluke & Lung worms & Pneumonia & Hepatitis \\
\hline Spring & 16 & 0 & 1 & 0 & 0 & 0 \\
Summer & 17 & 0 & 0 & 0 & 0 & 0 \\
Autumn & 8 & 0 & 0 & 0 & 0 & 0 \\
Winter & 7 & 0 & 0 & 0 & 0 & 0 \\
\hline Total & 48 & 0 & 1 & 0 & 0 & 0 \\
\hline
\end{tabular}

Table (7) Prevalance of infection in Camels according to seasons.

\begin{tabular}{lcccccc}
\hline Season & No. Examined & Hydatid cysts & Liver fluke & Lung worms & Pneumonia & Hepatitis \\
\hline Spring & 1 & 0 & 1 & 0 & 0 & 0 \\
Summer & 17 & 0 & 0 & 0 & 0 & 0 \\
Autumn & 4 & 0 & 0 & 0 & 0 & 0 \\
Winter & 2 & 0 & 0 & 0 & 0 & 0 \\
\hline Total & 24 & 0 & 0 & 0 & 0 & 0 \\
\hline
\end{tabular}

The economic losses due to condemnation of liver and lungs in Kirkuk abattoir were estimated depending on the number of completely and partially destroyed organs (Table 8).

In sheep, the total economic losses of completely and partially destroyed liver and lungs due to hydatid cysts in Iraqi diners were 1596000 fascioliasis in liver 1.370 .000 lungworm in lungs 158000 , pneumonia in lungs 496.000 and hepatitis 1220.000 diners. The overall economic losses due to condemnation of liver and lungs were 4840.000 Iraqi diners. In cattle, the economic losses due to condemnation of liver and lungs in Iraqi dinners was, in hydatid cysts 1778.000, fascioliasis 178.000.lung worms 198.000, hepatitis 1.430 .000 and pneumonia 248.000 . While in goats were fasciolias 80.000 lung worms 4000 , hepatitis 50.000 and pneumonia 22.000 , the overall economic loss due to condemnation of liver and lung during in Kirkuk abattoir was 10.435.000 Iraqi diners. 
Table (8) The economic losses due to condemnation of infected liver and lungs by helminthes, hepatitis and pneumonia.

\begin{tabular}{lccccccccc}
\hline Diseases & \multicolumn{3}{c}{$\begin{array}{c}\text { Sheep } \\
\text { Economic loss (Iraqi diners) }\end{array}$} & \multicolumn{2}{c}{ Economic loss (Iraqi diners) } & \multicolumn{2}{c}{ Economic loss (Iraqi diners) } \\
\cline { 2 - 10 } & Partial & Complete & Total & Partial & Complete & Total & Partial & Complete & Total \\
\hline $\begin{array}{l}\text { Hydatid cysts } \\
\text { Liver }\end{array}$ & 580.000 & 840.000 & 1.420 .000 & 520.000 & 1080.000 & 1600.000 & 0 & 0 & 0 \\
Lung & 66.000 & 110.000 & 176.000 & 76.000 & 102.000 & 178.000 & 0 & 0 & 0 \\
\hline Total & 646.000 & 950.000 & 1.596 .000 & 596.000 & 1182.000 & 1778.000 & & & \\
\hline $\begin{array}{l}\text { Fascioliasis } \\
\text { Liver }\end{array}$ & 630.000 & 740.000 & 1.370 .000 & 760.000 & 1020.000 & 1780.000 & 30.000 & 50.000 & 80.000 \\
$\begin{array}{l}\text { Lung worm } \\
\text { Lung }\end{array}$ & 68.000 & 90.000 & 158.000 & 78.000 & 120.000 & 198.000 & 0 & 4000 & 4000 \\
$\begin{array}{l}\text { Hepatitis } \\
\text { Liver } \\
\begin{array}{l}\text { Pneumonia } \\
\text { Lung }\end{array}\end{array}$ & 660.000 & 560.000 & 1220.000 & 490.000 & 940.000 & 1.430 .000 & 0 & 50.000 & 50.000 \\
\hline Total & 196.000 & 300.000 & 496.000 & 88.000 & 160.000 & 248.000 & 6000 & 1600 & 22.000 \\
\hline
\end{tabular}

\section{Discussion}

The occurrence of parasitic infection in an area is influenced by multifactor system which comprises hosts, parasitic and environmental effects. Parasitic infection causes considerable impact on the economy of live stock industry.

The number of sheep slaughtered in Kirkuk slaughter house was highest than other animals, this reflects that people in Kirkuk prefer sheep meat than other animals. The low number of buffalos and camels slaughtered because these animals are not common in this governorate.

The highest number of sheep slaughtered in spring season may be related to season of parturition of sheep and preference of people to young fresh meat, as lamb's meat during spring season.

The rate of hydatid cysts in this study was $0.77 \%$ in sheep and $1.75 \%$ in cattle which was lower than that reported in Baghdad (5) who reported $4.5 \%$ in sheep and $5.0 \%$ in cattle in Baghdad slaughter house. It is identical to study in Kirkuk (7) who found $1.17 \%$ for sheep while it was lower than reported for cattle $4.38 \%$. The difference between two studies may be related to period of study. No hydatid cysts were observed among slaughtered goats, this may be due to goats is more resistant to hydatidosis than other animals. Although low rate of hydatidosis $0.32 \%$ was reported in goats in Kirkuk slaughterhouse in 2006 (7). Also no hydatid observed among buffaloes and camels may be due to less number involved in this study as only 48 buffaloes and 24 camels were slaughtered during the period of this study.

Comparing the results of this study with that reported in other countries. In Syria (15) studied the epidemiology of hydatidosis among 1515 cattle, 14302 Awassi sheep and 1650 goats, found that $4.2 \%$ cattle $6.9 \%$ sheep and $12.7 \%$ goats were infected with hydatid cysts. In Iran (3) recorded the prevalence of sheep liver hydatid cysts at the municipal slaughterhouse of Tabriz, Northern region of Iran was $23.57 \%$.

In Arezzo slaughter-house in Italy (16) found the incidence of sheep hydatidosis, point out that from $47 \%$ of cases at least organ is parasitized the mostly trucked organ were liver and lungs and in lower percentage was in muscles kidneys and spleen,

In Bangladesh (17) examined 12344 goats, he found $1024(8.29 \%)$ were infected with hydatidosis. The incidence of infection by organ was liver $36.72 \%$, lung $32.03 \%$ spleen $4.69 \%$, heart $3.13 \%$, kidney $1.56 \%$,omentum $0.78 \%$ and both liver and lungs $21.09 \%$. Regarding the rate of hydatidosis in buffalos (18) examined 439 buffalos in Bangladesh, found $42.36 \%$ were infected. The rate of infection recorded in the liver $28.47 \%$ lungs $32.80 \%$, spleen $3.22 \%$, heart $2.15 \%$, kidney $1.08 \%$, omentum $0.54 \%$, and both liver and lungs $3.1 \%$.

In Kuwait (19) and found the rate of hydatidosis in 293 indigenous camel for period from February 1982 to April 1983 was $39.6 \%$.

The rate of fascioliasis among slaughtered sheep in Kirkuk municipal slaughterhouse was $0.77 \%$. It is lower than that observed in Baghdad 7.1\% (9) and in Mosul $16.5 \%$ (20) while it was higher than that reported in Sulaimania $0.13 \%$ (21) and Mohammad and in Kirkuk $0.50 \%(7)$.

The lower rate of fascioliasis in this study might be due to low rates of snails intermediate host in Kirkuk. The snails are widely distributed only in Al-Hawija district (9). 
The distribution of fascioliasis in cattle according to season, it was distributed throughout the year. In Sulaimania slaughter-house Kadir and Mohammed (22) found the highest rate was in November, this might be related to difference in geographical distribution, sample size and period of study. In Babylon Al-Delimi (11) found the highest rate in summer and lowest in winter months, this may be due to different in geographical distribution variation in environmental conditions.

In goats fascioliasis was also distributed in all seasons, with the highest rate was in winter season, this is in agreement with finding of study in Kirkuk (7).

In buffaloes fascioliasis, observed only in one case, and not observed in any The distribution of fascioliasis in buffaloes and camels is not significant due to small number of these animals slaughtered in kirkuk In Egypt (23) reported that the overall rate of fascioliasis among slaughtered animals were $2.02 \%$ for sheep and goats, $3.54 \%$ for cattle and $1.58 \%$ for buffalos.

The total economic losses due to partial or complete condemnation of sheep liver and lungs infected with hydatid cyst was (4.840000) Iraqi diners (40333 US dollars). Most of previous studies that involved economic losses resulting from infection of sheep with liver flukes indicate that the greatest part of this loss due to complete or partial destruction of liver infected with Fasciola species (9, 10). The economic loss due to condemnation of liver in fascioliasis (1,370,000 Iraqi diners (11416.6 US dollars), is higher than that reported in Sulaimania governorate (853.300) Iraqi diners (7110.8) US dollars

In cattle the overall economic loss due to partial or complete destruction of liver and lungs in all diseases were: In Fascioliasis the total economic loss due to condemnation of cattle liver was $1.780 .000 / 0$ Iraqi diners (14833.3 US dollars. this is lower than that reported in cattle in Sulaimania province which reached 22566840 Iraqi diners (16119.17 US dollars) but higher than that recorded In Baghdad (9) in Baghdad (88407 US dollars) and in Basra (10) it reached (98521.5 US dollars), because of great differences in exchange in Iraqi diners into US dollars between previous studies and the present study.

\section{References}

1. Soliman MFM. Epidemiological review of human and animal fascioliasis in Egypt. J Infect Developing countries 2008; 2 (3): 182189.

2. Lotfy A, Youssef H, Nassar A, Abdel-Aziz M. Fascioliasis in slaughtered animals. The incidence and public health importance. Fleischwirtshaft 1995; 75 (6): 803-804.
3. Ghazani MHM, Valilou MR, Kharati FB, Zirak K. Prevalance of sheep liver hydatid cyst in the Northwest Region. AJAVA 2008; 3 : 30-35

4. Eckert J, Deplazes P. Biological, epidemiological and clinical aspects of echinococcosis. Microbiol Rev 2004; 17:107-135.

5. Wajdi N, Nasir JM. Studies on the parasitic helminthes of slaughtered animals in Iraq. Parasitic helminthes of the liver of herbivores. Ann Trop Med Parasitol 1983; 77: 333-335.

6. Molan AL, Saeed ISA. Survey of hepatic and pulmonary helminthes and cestode larvae in goats and cow of Arbil province. J Agric Water Resource 1988; 105-114.

7. Kadir MA, Rasheed SA. Prevalence of some parasitic helminthes among slaughtered ruminants in Kirkuk,Iraq. Iraqi J Vet Sci 2008; 22(2):81-85.

8. Altaif KI. Observation on the incidence seasonal variation of some helminthes eggs and larvae in sheep in Iraq. Bull End Dis 1970; 12: 99-104.

9. Al-Barwari SE. A survey on the liver infections with $F$. gigantica among slaughtered animals in Iraq. Bull End Dis 1978; 18: 75-92.

10. Mahdi NK, Al-Baldawi FAK. Hepatic fascioliasis in the abattoir of Basrah. Ann Trop Med Parasitol 1987; 81: 377- 379.

11. Al-Delimi JK. Epidemiological and immunological study for F. gigantica among cattle in Babylon province. Ph.D. Thesis College Vet Med Univ. Baghdad, 2005.

12. Mather PB, Karim A, Al-Fathyl F. Observation on the incidence of some important helminthes in sheep in northern Iraq. VNDP/ FAO Development of liverstock in Northern Iraq. 71/5H2 (Cited in Karim MA working paper, Animal HLTH Res Laab 1975; Mosul Box 98 Iraq)

13. Nonnemaker JM, Schontz PM. Economic evaluation technique as tools for planning and evaluation of echinococcosis in Africa and Middle Eastern countries with special reference to Morocco. Anderson EL Ouhelli H Kachani M (Eds) Brigham Young University Print Services, 1997; P. 319.

14. Niazi AD. Statistical analysis in Medical Research. $2^{\text {nd }}$ Ed. College of Medicine, Nahrin University, Baghdad, Iraq 2004; P73-98.

15. Geblawi, R. Epidemiology of hydatidosis in sheep, goats and cattle in Syria. The 11th. Sci. Cong. Fac. Vet.Med. Assiut Univ, Egypt, 2004.

16. Caterina, B1 The $12^{\text {th }}$. Congress Mediterranean Federation for Health and Production of Ruminants. 16-19 Eylul, Istanbul, Turkey, 2004.

17. Shamsul Islam AWM. Hydatid diseases in goats in Baghdadesh, Vet. Parasiol; 7 (2): 103-107.

18. Shamsul-Islam AWM. Hydatidosis in buffaloes in Bangladesh. Rev Sci TechOff Epiz 1982; 1 (2): 435-441.

19. Abdul-Salam JM, Farah MA. Hydatidosis in buffaloes and camels in Kuwait. Parasitol Res1988; 74 (3): 267-27.

20. Al-Bayati MM. Study in epidemiology and histopathology of liver fluke in sheep in Mosul. MSc Thesis, College of Vet. Med, University of Baghdad, 1986.

21. Kadir M, Mohammed A. Prevalence of fascioliasis in sheep in Sulaimania Abattoir- Sulaimania- Iraq. 13 ${ }^{\text {th }}$. Sci Cong Fac Vet Med Assiut Univ Egypt, 2008.

22. Kadir MA, Mohammed A. Prevalence of fascioliasis in cattle in Sulaimania Abattoir- Sulaimania- Iraq $13^{\text {th }}$ Sci Cong Fac Vet Med Assiut Univ Egypt, 2008.

23. Haridy FM, Ibrahim BB, Morsy TA, El-Sharkawy IM. Fascioliasis an increasing zoonotic disease in Egypt. J Egypt Soc Parasitol 1999; 29 (1): $35-48$. 